\title{
Preparação de Nanopartículas Poliméricas a partir de Polímeros Pré-formados - Parte II
}

\author{
Eliana B. Souto \\ Faculdade de Ciências da Saúde, UFP \\ Centro de Genómica e Biotecnologia, Universidade de Trás-os-Montes e Alto Douro \\ Patrícia Severino \\ Faculdade de Ciências da Saúde, UFP \\ Departamento de Processos Biotecnológicos, UNICAMP \\ Maria Helena A. Santana \\ Departamento de Processos Biotecnológicos, UNICAMP
}

\begin{abstract}
Resumo: Nanopartículas poliméricas produzidas a partir de polímeros pré-formados, como os poliésteres alifáticos, têm sido amplamente utilizadas para incorporar, principalmente, princípios ativos lipofílicos. A produção das nanopartículas (nanocápsulas e nanosferas) por polímeros pré-formados pode ser realizada por emulsificação-evaporação do solvente, por deslocamento do solvente, por salting-out ou por emulsificação-difusão do solvente. Estes métodos de produção estão revisados e descritos neste artigo, evidenciando os parâmetros tecnológicos que interferem nas características físico-químicas das nanopartículas, como a solubilidade do princípio ativo, o volume e pH do meio de polimerização, a massa molar e concentração do monômero e a natureza e concentração do tensoativo.
\end{abstract}

Palavras-chave: Polímeros pré-formados, emulsificação-evaporação do solvente, por deslocamento do solvente, por salting-out ou por emulsificação-difusão do solvente.

\section{Preparation of Polymeric Nanoparticles from Pre-Formed Polymers - Part II}

Abstract: Polymeric nanoparticles have been produced by pre-formed polymers using aliphatic polyesters, which have been widely used to incorporate lipophilic drugs. The production of nanoparticles (nanospheres and nanocapsules) by pre-formed polymers can be performed by emulsification-solvent evaporation, solvent replacement, salting out or by emulsification-solvent diffusion. These methods are reviewed and discussed in this article, highlighting the technological parameters that influence the physicochemical characteristics of nanoparticles, such as the solubility of drug, the volume and $\mathrm{pH}$ of polymerization, the molecular weight and monomer concentration and the nature and concentration of the surfactant.

Keywords: Pre-formed polymers, emulsification-solvent evaporation, solvent replacement, salting out or by solvent emulsification-diffusion.

\section{Introdução}

Os métodos de preparação de nanopartículas a partir de polímeros pré-formados, como os poliésteres alifáticos, são particularmente adaptados para incorporar princípios ativos lipofílicos ${ }^{[1]}$. As nanopartículas devem ser preparadas com base numa razão princípio ativo/polímero adequada à obtenção de uma eficiência de encapsulação elevada e toxicidade reduzida. Em regra, a escolha de um método de preparação é determinada pelas características de solubilidade do princípio ativo ${ }^{[2-4]}$. Em comparação com os métodos de produção de nanopartículas poliméricas a partir da polimerização de monômeros, a preparação utilizando polímeros pré-formados é mais facilmente controlável, de maior rendimento, e pode ser realizada por emulsificaçãoevaporação do solvente ${ }^{[5]}$, por deslocamento do solvente ${ }^{[6]}$, por salting-out ${ }^{[7]}$ ou por emulsificação-difusão do solvente ${ }^{[8]}$.

\section{Emulsificação-Evaporação do Solvente}

O método denominado emulsificação-evaporação do solvente envolve, inicialmente, a preparação de uma emulsão do tipo O/A e origina nanosferas ${ }^{[9]}$.
Inicialmente, prepara-se uma fase orgânica, constituída por um solvente orgânico apolar no qual é dissolvido o polímero e incluído o princípio ativo por dissolução ou dispersão. Prepara-se também uma fase aquosa, que contém um tensoativo do tipo O/A, como, por exemplo, o acetato de polivinila (PVA) ${ }^{[5]}$. Submetese à emulsificação, por agitação de ambas as fases, seguindo-se a exposição da emulsão recém-preparada a uma fonte de energia elevada, como, por exemplo, os ultrassons ou a homogeneização a alta pressão. A agitação da emulsão é a etapa determinante para a obtenção das nanosferas e deve ser realizada antes da precipitação do polímero, de modo a serem obtidas gotículas de fase interna de dimensões coloidais. Por fim, promove-se a remoção do solvente orgânico, ocorrendo a precipitação do polímero na fase externa aquosa e consequente formação das nanosferas ${ }^{[10]}$.

Os princípios ativos hidrossolúveis, para poderem ser incorporados por dispersão na fase orgânica, podem, em alternativa, ser dissolvidos numa fase aquosa, que, posteriormente, vai constituir a fase interna de uma emulsão múltipla $\mathrm{A} / \mathrm{O} / \mathrm{A}^{[11,12]}$. Este processo é particularmente adequado para a incorporação de

Autor para correspondência: Eliana B. Souto, Faculdade de Ciências da Saúde, Universidade Fernando Pessoa - UFP, Rua Carlos da Maia, 296, CEP 4200150 Porto, Portugal, e-mail: eliana@ufp.edu.pt 
peptídeos e proteínas em nanosferas. Neste caso, como a fase aquosa interna tem tendência para coalescer durante a agitação, a presença de um tensoativo na fase orgânica é essencial para aumentar a estabilidade da emulsão primária $\mathrm{A} / \mathrm{O}$ e, em consequência, da emulsão múltipla A/O/A ${ }^{[13]}$.

Para preparar nanosferas são utilizados tensoativos na fase externa aquosa, de modo a obter dispersões estáveis, embora se forem utilizados polímeros com grupos catiônicos pode ser obviada a sua utilização. O tensoativo mais adequado é aquele que promove uma redução maior da energia livre interfacial, diminuindo a tendência à coalescência e à aglomeração das gotículas emulsificadas. O seu valor de Equilíbrio Hidrofílico Lipofílico (EHL) deverá estar compreendido entre 8 e $18^{[14]}$.

Os tensoativos utilizados na fase externa aquosa são, em regra, o $\mathrm{PVA}^{[15]}$ e a albumina ${ }^{[16]}$. O primeiro é dos poucos que evita a agregação das nanosferas durante a lavagem e a liofilização, embora não possa ser utilizado quando o produto se destina a administração intravenosa. A albumina é utilizada em substituição do PVA devido à sua biodegradabilidade. Na fase interna orgânica podem ser incluídos fosfolipídios ${ }^{[17]}$.

$\mathrm{Na}$ maior parte dos casos são usados solventes clorados para solubilizar o polímero, como o cloreto de metileno ou o clorofórmio, devido à sua baixa hidrossolubilidade, ao seu baixo ponto de ebulição e à sua capacidade de solubilização de um grande número de princípios ativos ${ }^{[18]}$. A maior desvantagem destes solventes orgânicos reside na sua toxicidade, pelo que, por vezes, são substituídos pelo acetato de etilo. A remoção do solvente orgânico é realizada a pressão reduzida ${ }^{[19]}$. Em alternativa, submetese a dispersão coloidal a uma agitação mecânica ou magnética, à pressão atmosférica e à temperatura ambiente. No final, é obtida uma dispersão aquosa de nanosferas, que são separadas por centrifugação, ultracentrifugação ou ultrafiltração. Em seguida, são lavadas com água deionizada ou com uma solução tampão e, por fim, liofilizadas ${ }^{[20]}$.

As características fisico-químicas das nanosferas obtidas por emulsificação-evaporação do solvente são afetadas por um conjunto de parâmetros tecnológicos, que incluem a solubilidade do princípio ativo, a natureza do solvente orgânico, a concentração do polímero, a natureza e a concentração do tensoativo, o modo e a duração da agitação da emulsão.

\section{Solubilidade do princípio ativo}

Este método apresenta-se limitado para a incorporação de princípios ativos hidrofílicos em nanosferas, devido à sua solubilidade elevada na fase externa aquosa ${ }^{[21]}$. Para este tipo de princípios ativos, o aumento da eficiência de encapsulação pode ser conseguido, quer pelo ajustamento do $\mathrm{pH}$ da fase aquosa, para valores superiores ao $\mathrm{pK}_{\mathrm{a}}$ do princípio ativo (prevenindo a sua ionização e retendo-o na fase interna orgânica), ou pela redução da duração da agitação e da respectiva velocidade. Uma outra estratégia consiste na preparação de emulsões múltiplas A/O/A ${ }^{[22]}$.

\section{Natureza e volume do solvente orgânico}

O solvente orgânico selecionado deverá ser apolar, ter capacidade para solubilizar o polímero e difundir-se facilmente através da fase aquosa, de modo a permitir a precipitação do polímero e a formação de nanosferas. A velocidade de difusão depende da solubilidade do solvente orgânico na fase externa aquosa e da sua velocidade de evaporação. Para a obtenção de nanosferas de dimensões reduzidas e com uma distribuição homogênea de tamanhos, deve utilizar-se, preferencialmente, um volume de solvente orgânico baixo ${ }^{[23,24]}$.

\section{Concentração do polímero}

O tamanho das nanosferas é determinado pela concentração do polímero na fase interna da emulsão. Para um determinado volume da fase interna, o aumento da concentração do polímero aumenta a viscosidade dessa fase, obtendo-se nanosferas de maiores dimensões, devido à maior dificuldade de dispersão da fase interna na fase externa ${ }^{[25]}$.

\section{Natureza e concentração do tensoativo}

$\mathrm{Na}$ preparação de nanosferas por emulsificação-evaporação do solvente utiliza-se um tensoativo na fase aquosa externa, cuja natureza e concentração afetam as dimensões das nanosferas ${ }^{[26]}$. Quando o tensoativo utilizado tem baixa massa molar, como, por exemplo, o colato de sódio, as suas moléculas localizam-se, preferencialmente, à superfície das gotículas emulsificadas, pelo que um aumento da sua concentração aumenta a proteção das nanosferas contra a coalescência, resultando numa emulsificação mais eficaz e em nanosferas de menores dimensões. Quando se trata de um tensoativo de massa molar elevada, como, por exemplo, o PVA, o tamanho das nanosferas diminui com o aumento da concentração de PVA até à sua concentração micelar crítica (CMC). Quanto maior for a concentração de PVA, maior será o número de moléculas que se insere na superfície das gotículas emulsificadas. Os fosfolipídios podem também constituir uma alternativa como tensoativos na preparação de nanosferas, sendo neste caso, incluídos na fase orgânica da emulsão. A utilização de um sistema de tensoativos, em que um é incluído na fase interna orgânica, por exemplo, um fosfolipídios, e outro na fase externa aquosa, por exemplo, o PVA, constitui outra estratégia para a preparação de nanosferas de dimensões reduzidas ${ }^{[27]}$.

\section{Agitação}

A emulsificação de um solvente orgânico apolar numa fase aquosa, por agitação, origina, na maioria dos casos, gotículas com dimensões entre 2 e $5 \mu \mathrm{m}$. Para se obterem gotículas com dimensões inferiores a $1 \mu \mathrm{m}$ torna-se necessário submeter a emulsão a uma tensão de cisalhamento elevada. Além disso, a difusão do solvente orgânico apolar no meio da fase aquosa é muito lenta e limita a concentração do polímero na interface, pelo que, recorrendo a ultrassons ou a homogeneização a alta pressão, é possível reduzir o tamanho das gotículas da fase interna e, ao mesmo tempo, aumentar a superfície de contato entre ambas as fases ${ }^{[8]}$. A utilização de ultrassons proporciona a redução do diâmetro das nanosferas apresentando, no entanto, o risco de contaminação da dispersão coloidal por titânio e uma distribuição mais heterogênea de tamanhos, tornando o processo difícil de transposição de escala ${ }^{[28]}$.

\section{Deslocamento do Solvente}

O método de preparação de nanopartículas por deslocamento do solvente, consiste na precipitação ou deposição interfacial de um polímero pré-formado, uma vez que ocorre na interface de uma emulsão O/A. Por esta razão, o método é igualmente encontrado na literatura sob a denominação de nanoprecipitação ${ }^{[9,29]}$. Neste método, a fase interna é constituída por um polímero dissolvido num solvente orgânico polar, como, por exemplo, a acetona ou o acetonitrila, no qual se encontra dispersa ou dissolvida o princípio ativo $^{[30]}$. A utilização de um tensoativo incluído na fase orgânica como, por exemplo, um fosfolipídio, pode ser adequada para prevenir a coalescência das gotículas. A fase externa é formada por uma solução aquosa, contendo um tensoativo do tipo O/A como, por exemplo, o PVA ou um poloxâmer. Procede-se à dispersão da 
fase interna na fase externa, sob agitação magnética, ocorrendo uma emulsificação espontânea com a formação de um sistema opalescente devido à miscibilidade de ambas as fases. Segue-se a remoção do solvente orgânico a pressão reduzida, formando-se as nanopartículas, como resultado da difusão rápida do solvente do polímero, através da fase aquosa ${ }^{[31]}$.

A utilização de co-polímeros anfipáticos formados por copolímeros de poli(ácido lático)-co-(ácido glicólico) (PLGA) e cadeias hidrofílicas de polietilenoglicol (PEG) ou PVA, bem como polímeros eletricamente carregados, pode retirar o uso de tensoativos, uma vez que, em solução, este tipo de polímeros forma espontaneamente estruturas do tipo micelar. No entanto, quando se pretende preparar nanopartículas revestidas com cadeias hidrofílicas, o método de emulsificação-evaporação do solvente é mais adequado, já que permite incluir uma maior quantidade de polímero hidrofílico à superfície das nanopartículas. Como ocorre a evaporação lenta do solvente, o método de preparação de nanopartículas a partir de polímeros pré-formados exposto anteriormente permite uma melhor organização das cadeias hidrofílicas ${ }^{[32]}$.

O método de deslocamento do solvente permite obter nanosferas ou nanocápsulas. São obtidas nanosferas quando o princípio ativo se encontra dissolvido ou disperso na solução orgânica polimérica. São obtidas nanocápsulas quando o princípio ativo é previamente dissolvido num óleo, e este, em seguida, é emulsificado na solução orgânica polimérica antes da dispersão da fase interna na fase externa da emulsão $0^{[33]}$.

\section{Nanosferas}

Para se preparar nanosferas pelo método de deslocamento do solvente, o princípio ativo deve ser dissolvido ou disperso na fase orgânica, juntamente com o polímero. Este método permite controlar melhor as dimensões das nanosferas, em comparação com o método que se baseia na emulsificação-evaporação do solvente, permitindo, por isso, reduzir o seu tamanho. As características fisico-químicas das nanosferas obtidas por deslocamento do solvente são afetadas por um conjunto de parâmetros tecnológicos, que incluem a solubilidade do princípio ativo, a natureza do solvente orgânico, a massa molar e a concentração do polímero, a concentração do tensoativo, a temperatura da fase externa, as dimensões do dispositivo e a velocidade de injeção da fase interna na fase externa ${ }^{[25,34]}$.

\section{Solubilidade do princípio ativo}

Em regra, o método de deslocamento do solvente é usado para preparar nanosferas contendo princípios ativos lipofílicos. Os princípios ativos hidrofílicos têm afinidade reduzida para os polímeros utilizados, originando nanosferas com uma eficiência de encapsulação baixa, uma vez que este tipo de princípios ativos tende a difundir-se da fase interna para a fase externa, durante o processo de emulsificação espontânea. Os princípios ativos lipofílicos não sofrem difusão para a fase externa, pelo que as respectivas nanosferas apresentam uma eficiência de encapsulação mais elevada ${ }^{[35]}$. A difusão para o meio externo pode ser diminuída pelo aumento da lipofilia do princípio ativo por formação de pares iônicos com fosfolipídios carregados eletricamente, por conjugação com ácidos gordos de cadeia hidrocarbonada longa ou por manipulação do $\mathrm{pH}$ da fase aquosa externa, para um valor de menor hidrossolubilidade do princípio ativo. Em regra, quanto maior for a quantidade de princípio ativo utilizada na preparação, maiores serão as dimensões e a capacidade de carga das nanosferas ${ }^{[36]}$.

\section{Natureza do solvente orgânico}

A fase interna é constituída por um solvente orgânico polar. No entanto, pode utilizar-se um sistema de co-solventes constituído por acetona e por um solvente orgânico apolar. Mantendo a concentração do polímero e o volume do solvente apolar constantes, verifica-se um aumento do tamanho médio das nanosferas, à medida que o volume de acetona diminui. Tal deve-se ao aumento da viscosidade da fase orgânica, que dificulta a formação adequada das nanosferas. Por esta razão, num sistema de co-solventes, o aumento do volume de acetona origina nanosferas de dimensões menores ${ }^{[34]}$.

\section{Massa molar e concentração do polímero}

Os polímeros de massa molar elevada precipitam mais rapidamente aquando da adição da fase interna na fase externa, permitindo aumentar a incorporação de princípios ativos hidrofílicos. Devido à difusão do solvente orgânico na fase externa, a concentração do polímero na solução orgânica aumenta e, em consequência, aumenta a viscosidade da solução polimérica remanescente. A velocidade de difusão do solvente orgânico depende do número de moléculas de polímero na fase interna, e do seu comportamento em solução. Então, para uma concentração elevada de polímero na fase orgânica, menor será a velocidade de difusão e maior o tamanho das nanosferas resultantes do fluido. Uma concentração polimérica mais baixa conduz ao aumento da velocidade de difusão do solvente, à redução do tamanho médio das gotículas da dispersão resultante e, em consequência, à obtenção de nanosferas de menores dimensões ${ }^{[32]}$.

\section{Natureza e concentração do tensoativo}

A presença de um agente tensoativo na fase orgânica pode ser adequada para se obter nanosferas de menores dimensões. Em regra, o aumento da concentração de tensoativo na fase externa, até à sua $\mathrm{CMC}$, é acompanhado pela diminuição das dimensões das nanosferas. Acima da CMC, a concentração do tensoativo não afeta as dimensões, uma vez que a energia interfacial permanece praticamente constante ${ }^{[37]}$.

\section{Temperatura da fase externa}

Durante o processo de emulsificação espontânea, o aumento da temperatura da fase externa conduz à redução da tensão interfacial e, por isso, origina nanosferas de dimensões menores.

Dimensões do dispositivo e velocidade de injeção da fase interna na fase externa

As dimensões das nanosferas preparadas por deslocamento do solvente são controladas pelo calibre da agulha (superfície de injeção) utilizada para dispersar a fase interna na fase externa. A difusão do solvente orgânico, a partir das gotículas da fase interna orgânica para a fase externa aquosa é o principal fator responsável pela precipitação do polímero e consequente formação das nanosferas $^{[38]}$.

\section{Nanocápsulas}

Um problema frequente na incorporação dos princípios ativos lipofílicos, por métodos que envolvem a dispersão de um solvente orgânico no meio de uma fase aquosa, relaciona-se com a sua precipitação nesta última fase. Para ultrapassar este problema, pode recorrer-se à preparação de nanocápsulas, que veiculam o princípio ativo dissolvido num núcleo oleoso ${ }^{[39]}$. A preparação de nanocápsulas implica a obtenção de uma solução oleosa, formada pelo princípio ativo dissolvido num óleo adequado. O óleo selecionado deverá ser um solvente adequado para o princípio ativo, de modo a prevenir a sua difusão e cristalização na fase externa aquosa, durante a preparação das nanocápsulas, e não deverá degradar o polímero. Podem ser utilizados óleos vegetais, parafina líquida, compostos puros, como, por exemplo, o benzoato de benzilo ou o oleato de 
etilo, ou misturas de triacilgliceróis, como o Miglyol $^{\circledR} 810,812,829$ ou $840^{[40,41]}$.

A solução oleosa recém-preparada é adicionada a uma solução polimérica num solvente orgânico polar, que, na maioria dos casos, é a acetona. Esta solução, em seguida, é emulsificada numa fase aquosa, que contém um tensoativo do tipo O/A. Na preparação das nanocápsulas é apropriado utilizar-se um sistema de agentes tensoativos, isto é, um incluído na fase orgânica como, por exemplo, um fosfolipídio, e outro incluído na fase aquosa externa como, por exemplo, um poloxâmer, de modo a reduzir as dimensões e aumentar a estabilidade da dispersão coloidal ${ }^{[42]}$. As características fisico-químicas das nanocápsulas obtidas por deslocamento do solvente são afetadas por um conjunto de parâmetros tecnológicos, que incluem a solubilidade do princípio ativo, a concentração do agente tensoativo e a natureza e volume do óleo.

\section{Solubilidade do princípio ativo}

A solubilidade do princípio ativo na fase oleosa é um requisito essencial para obter nanocápsulas com uma eficiência de encapsulação elevada. Quando maior for o coeficiente de partilha óleo/água, menor será a tendência do princípio ativo para abandonar a fase oleosa. Os princípios ativos hidrossolúveis sofrem difusão para a fase aquosa, originando nanocápsulas com eficiência de encapsulação muito reduzidas. Quanto maior for a quantidade de princípio ativo dissolvida na solução oleosa, maior será a capacidade de carga das nanocápsulas ${ }^{[43,44]}$.

\section{Concentração do tensoativo}

Para se obter dispersões aquosas estáveis de nanocápsulas é necessário incluir uma quantidade mínima de fosfatidilcolina na fase oleosa, cerca de $0,3 \%\left(\mathrm{~m} . \mathrm{v}^{-1}\right)$, para dispersões contendo $2,5 \%\left({\mathrm{v} . \mathrm{v}^{-1}}^{-}\right)$de fase oleosa, e um tensoativo do tipo O/A na fase externa aquosa, como, por exemplo, um poloxâmer. O aumento da concentração do tensoativo na fase externa conduz, em regra, à redução das dimensões das nanocápsulas ${ }^{[45]}$.

\section{Natureza e volume do óleo}

As nanocápsulas preparadas com benzoato de benzilo são mais ácidas, devido à existência de ácidos livres no núcleo oleoso, que podem aumentar a degradação do polímero ${ }^{[44]}$. A parafina líquida e o dodecano apresentam uma tensão interfacial elevada, o que dificulta a difusão rápida da fase orgânica na fase aquosa, como resultado da sua miscibilidade reduzida em acetona. Por esta razão, estes óleos são utilizados para aumentar o tamanho médio das nanocápsulas, uma vez que a coalescência é suficientemente elevada para competir com a emulsificação espontânea ${ }^{[46]}$.

Óleos altamente viscosos são muito resistentes às tensões de corte aplicadas durante a emulsificação, pelo que maior será o tamanho das gotículas oleosas e maior será o tamanho das nanocápsulas obtidas. Não é possível estabelecer uma relação entre a densidade do óleo e as dimensões das nanocápsulas. O Miglyol® 810 e 812, que são constituídos por triacilgliceróis de cadeia média, e o oleato de etilo, parecem ser os óleos mais adequados para a administração intravenosa, devido ao tamanho menor das nanocápsulas obtido ${ }^{[47]}$.

\section{Salting-Out}

O método de salting-out baseia-se na separação de um solvente hidromiscível, de uma solução aquosa, através de um efeito de salting-out, que resulta na formação de nanosferas ${ }^{[7]}$. Prepara-se uma emulsão do tipo O/A, através da adição de uma fase interna, formada por uma solução do polímero num solvente orgânico polar como, por exemplo, a acetona ou o tetrahidrofurano, contendo o princípio ativo dissolvido ou disperso, a uma fase externa formada por uma solução aquosa saturada de um eletrólito ou não-eletrólito, contendo um tensoativo, como, por exemplo, o PVA. A emulsão O/A é preparada, sob agitação intensa, à temperatura ambiente. Em seguida, a emulsão é diluída num volume adequado de água deionizada ou de uma solução aquosa, de modo a permitir a difusão do solvente orgânico para a fase externa, a precipitação do polímero e a consequente formação das nanosferas. A separação das nanosferas do excesso de eletrólito e do tensoativo é realizada por ultracentrifugação ou ultrafiltração, obtendo-se, no final, uma dispersão aquosa de nanosferas ${ }^{[9]}$.

Em regra, as dimensões das nanosferas obtidas por este método variam entre 170 e $900 \mathrm{~nm}$. O tamanho médio pode ser ajustado para valores entre 200 e $500 \mathrm{~nm}$, variando a concentração polimérica da fase interna ou a razão volume da fase interna/volume da fase externa ${ }^{[48]}$. As características físico-químicas das nanosferas obtidas por salting-out são afetadas por um conjunto de parâmetros tecnológicos, que incluem a solubilidade do princípio ativo, a natureza do solvente orgânico, a natureza do agente de salting-out e a concentração do tensoativo.

\section{Solubilidade do princípio ativo}

A preparação de nanosferas por salting-out origina maiores eficiências de encapsulação para princípios ativos lipofílicos devido à natureza orgânica da fase interna da emulsão. Os princípios ativos hidrofílicos são incorporados nas nanosferas por salting-out em menor extensão $0^{[49]}$.

\section{Natureza do solvente orgânico}

A acetona é o solvente orgânico normalmente utilizado, devido às suas propriedades solubilizantes e ao fato de ser facilmente removida de soluções saturadas de eletrólitos ${ }^{[50]}$. Outros solventes, como o tetrahidrofurano, o acetato de etilo ou o álcool isopropilo, também podem ser usados na preparação de nanosferas.

\section{Natureza do agente de salting-out}

A seleção do agente de salting-out é um fator importante, uma vez que afeta a incorporação dos princípios ativos. Este método encontra-se limitado a agentes de salting-out que não sofram precipitação devido à separação das nanosferas recém-preparadas. Quando se usa a acetona como solvente orgânico, podem ser usados como agentes de salting-out o $\mathrm{MgCl}_{2}, \mathrm{NaCl}$ ou $\mathrm{Mg}\left(\mathrm{CH}_{3} \mathrm{COO}\right)_{2}$. Quando a fase aquosa tem caráter ácido, o $\mathrm{MgCl}_{2}$ não pode ser utilizado como agente de salting-out, uma vez que é solúvel nesse meio. Além disso, quando se utiliza o $\mathrm{MgCl}_{2}$, não pode ser adicionada uma base forte, como o $\mathrm{NaOH}$, para modificar o $\mathrm{pH}$ da fase aquosa, pois, nesse caso, ocorre a precipitação de $\mathrm{Mg}(\mathrm{OH})_{2}^{[50]}$.

\section{Concentração do tensoativo}

Este método está limitado a tensoativos solúveis na fase aquosa externa e compatíveis com soluções aquosas saturadas. Em regra, é utilizado o PVA, cujo aumento da concentração na fase externa, diminui o tamanho das nanosferas. Este tensoativo parece também aumentar a estabilidade estereoquímica das nanosferas recém$\operatorname{preparadas}^{[47]}$.

\section{Emulsificação-difusão do Solvente}

O método de emulsificação-difusão do solvente pode ser considerado como uma modificação do método de salting-out, evitando-se o uso de sais e de processos de purificação ou lavagem das nanopartículas recém-formadas ${ }^{[23]}$.

O método envolve a preparação de uma emulsão do tipo O/A, cuja fase interna é constituída por um solvente orgânico parcialmente hidromiscível como, por exemplo, álcool benzílico, 
propilenocarbonato ou acetato de etilo, que é previamente saturado com água, de modo a assegurar um equilíbrio termodinâmico inicial de ambas as fases. O polímero é dissolvido no solvente saturado, formando-se uma fase orgânica na qual é disperso ou dissolvido o princípio ativo. Esta fase é emulsificada, sob agitação intensa, numa solução aquosa, contendo um tensoativo do tipo O/A, como, por exemplo, o PVA ou um poloxâmer. A adição subsequente de água ao sistema, provoca a difusão do solvente orgânico na fase externa. Dependendo do seu ponto de ebulição, o solvente pode ser eliminado por evaporação ou por ultrafiltração, obtendo-se, no final, a dispersão aquosa de nanopartículas ${ }^{[51]}$.

Podem ser obtidas nanosferas ou nanocápsulas por emulsificação-difusão do solvente. Para preparar nanocápsulas, o princípio ativo lipofílico é previamente dissolvido num óleo, que é adicionado, em seguida, ao solvente orgânico parcialmente hidromiscível. Quintanar-Guerrero et al. (1998) ${ }^{[3]}$ prepararam nanocápsulas com eficiência de encapsulação elevada, para princípios ativos lipossolúveis, como indometacina, progesterona, estradiol, clofibrato, clorambucil e vitamina E.

Este método permite preparar nanopartículas de dimensões compreendidas entre 80 e $900 \mathrm{~nm}$. Tem o inconveniente associado ao volume elevado de fase aquosa, que tem de ser eliminado da dispersão coloidal, e o risco de ocorrência de difusão dos princípios ativos hidrofílicos para a fase aquosa, durante a emulsificação ${ }^{[52]}$. As características físico-químicas das nanopartículas obtidas por emulsificação-difusão do solvente são afetadas por um conjunto de parâmetros tecnológicos, que incluem a solubilidade do princípio ativo, a concentração do polímero, a natureza e concentração do tensoativo e a agitação.

\section{Solubilidade do princípio ativo}

A preparação de nanopartículas, quer nanosferas, quer nanocápsulas, origina eficiências de encapsulação mais elevadas para princípios ativos lipossolúveis, uma vez que os hidrossolúveis evidenciam uma maior tendência para se difundirem, juntamente com o solvente orgânico para a fase externa aquosa.

\section{Concentração do polímero}

O aumento da concentração do polímero conduz a um aumento da viscosidade da fase interna, resultando nanopartículas de maiores dimensões e uma distribuição mais heterogênea de tamanhos ${ }^{[53]}$.

\section{Natureza e concentração do tensoativo}

A seleção do tensoativo depende da sua capacidade em estabilizar a emulsão, para assegurar a formação das nanopartículas. A concentração do agente tensoativo presente na fase externa aquosa influencia as dimensões das nanopartículas. $\mathrm{O}$ aumento da sua concentração, em regra, origina nanopartículas de menores dimensões, devido à estabilização de uma área interfacial maior ${ }^{[54]}$.

\section{Agitação}

Durante a emulsificação da fase orgânica na fase aquosa, o aumento da velocidade de agitação provoca uma diminuição das dimensões das nanopartículas. A agitação, durante a etapa de diluição, deve ser suficiente para homogeneizar a emulsão, caso contrário, a distribuição de tamanhos torna-se mais heterogênea ${ }^{[53]}$.

\section{Conclusão}

O uso de métodos de preparação de nanopartículas a partir de polímeros pré-formados, como os poliésteres alifáticos na produção de nanopartículas é uma aplicação consolidada na farmacêutica, sendo particularmente adaptados para incorporar princípios ativos lipofílicos. As metodologias empregadas para preparação dessas nanopartículas, como emulsificação-evaporação do solvente, por deslocamento do solvente, por salting-out ou por emulsificaçãodifusão do solvente do qual permitem a melhor escolha a partir da solubilidade do princípio ativo, da razão princípio ativo/polímero adequada à obtenção de uma eficiência de encapsulação elevada e toxicidade reduzida. Essa abordagem deve ser sempre considerada como uma opção para aplicações de liberação controlada e direcionamento específico de princípios ativos e por várias vias de administração, promovendo as vantagens de proteção do princípio ativo, melhor biodisponibilidade e menor toxicidade, proporcionando maior conforto e adesão ao tratamento dos pacientes.

\section{Agradecimentos}

Os autores agradecem à Fundação para a Ciência e a Tecnologia (FCT) do Ministério da Ciência e Tecnologia (PTDC/SAUFAR/113100/2009), à Fundação de Amparo à Pesquisa do Estado de São Paulo (FAPESP/Brasil) e à Coordenação de Aperfeiçoamento de Pessoal de Nível Superior (Capes, Brasil).

\section{Referências Bibliográficas}

1. Severino, P., Pinho, S. C.; Santana, M. H.; \& Souto, E. B. - Polímeros, in press (2011).

2. Vauthier, C. \& Bouchemal, K. - Pharm. Res., 26, p.1025 (2009). PMid:19107579. http://dx.doi.org/10.1007/s11095-008-9800-3

3. Quintanar-Guerrero, D.; Allemann, E.; Doelker, E. \& Fessi, H. - Pharm. Res., 15, p. 1056 (1998). PMid:9688060. http://dx.doi. org/10.1023/A:1011934328471

4. Silva, A. C.; Santos, D.; Ferreira, D. C. \& Souto, E. B. "Advances in nanoparticulate carriers for oral delivery of peptides and proteins: polymeric versus lipid nanoparticles", in: Encyclopaedia of Nanoscience and Nanotechnology, H.S. Nalwa (ed.), Los Angeles (2010).

5. Wang, J.; Liu, W.; Tu, Q.; Song, N.; Zhang, Y. \& Nie, N. Biomacromolecules, 10, p. 228 (2010).

6. Tahara, K.; Furukawa, S.; Yamamoto, H. \& Kawashima Y. - Int. J. Pharm., 392, p. 311 (2010). PMid:20347023. http://dx.doi. org/10.1016/j.ijpharm.2010.03.042

7. Wheatley, M. A. \& Lewandowski, J. - Mol. Imaging., 9, p. 96 (2010). PMid:20236607.

8. Ozturk, K.; Caban, S.; Kozlu, S.; Kadayifci, E.; Yerlikaya, F. \& Capan, Y. - Pharmazie, 65, p. 665 (2010). PMid:21038843.

9. Quintanar-Guerrero, D., Allemann, E.; Fessi, H. \& Doelker, E. - Drug Dev. Ind. Pharm., 24, p. 1113 (1998). PMid:9876569. http://dx.doi. org/10.3109/03639049809108571

10. Essa, S.; Rabanel, J. M. \& Hildgen P. - Int. J. Pharm., in press (2011). PMid:21458551. http://dx.doi.org/10.1016/j.ijpharm.2011.02.039

11. Tewes, F.; Munnier, E.; Antoon, B.; Ngaboni, O. L.; Cohen-Jonathan, S.; Marchais, H.; Douziech-Eyrolles, L.; Souce, M.; Dubois, P. \& Chourpa, I. - Eur J. Pharm. Biopharm., 66, p. 488 (2007). PMid:17433641. http:// dx.doi.org/10.1016/j.ejpb.2007.02.016

12. Li, X.; Xu, Y.; Chen, G.; Wei, P. \& Ping, Q. - Drug Dev. Ind. Pharm., 34, p. 107 (2008). PMid:18214762. http://dx.doi. org/10.1080/03639040701484593

13. Slutter, B.; Bal, S.; Keijzer, C.; Mallants, R.; Hagenaars, N.; Que, I.; Kaijzel, E.; van Eden, W.; Augustijns, P.; Löwik, C.; Bouwstra, J.; Broere, F.; Jiskoot, W. - Vaccine., 28, p. 6282 (2010). PMid:20638455. http://dx.doi.org/10.1016/j.vaccine.2010.06.121

14. Anton, N.; Benoit, J. P. \& Saulnier, P. - J. Control. Release., 128, p. 185 (2008). PMid:18374443. http://dx.doi.org/10.1016/j.jconrel.2008.02.007 
15. Scholes, P. D.; Coombes, A. G.; Illum, L.; Davis, S. S.; Watts, J. F.; Ustariz, C.; Vert, M.; Davies, M. C. - J. Control. Release, 59, p. 261 (1999). http://dx.doi.org/10.1016/S0168-3659(98)00138-2

16. Shen, Z. Y.; Ma, G. H.; Dobashi, T.; Maki, Y. \& Su, Z. G. - Int J. Pharm., 346, p.133 (2008). PMid:17651929. http://dx.doi. org/10.1016/j.jpharm.2007.06.004

17. Liu, Y.; Pan, J. \& Feng, S. S. - Int. J. Pharm., 395, p. 243 (2010). PMid:20472049. http://dx.doi.org/10.1016/j.ijpharm.2010.05.008

18. Liu, J.; Qiu, Z.; Wang, S.; Zhou, L. \& Zhang, S. - Biomed. Mater., 6, p. 065002 (2010). PMid:20924138. http://dx.doi.org/10.1088/1748$6041 / 5 / 6 / 065002$

19. Quintanar-Guerrero, D.; Allemann, E.; Fessi, H. \& Doelker, E. - Int. J. Pharm., 188, p. 155-164 (1999). http://dx.doi.org/10.1016/S03785173(99)00216-1

20. Desgouilles, S.; Vauthier, C.; Bazile, D.; Vacus, J.; Grossiord, L.; Veillard, M.; Couvreur, P. - Langmuir., 19, p. 9504 (2003). http:// dx.doi.org/10.1021/la034999q

21. Corrigan, O. I. \& Li, X. - Eur. J. Pharm. Sci., 37, p. 477 (2009). PMid:19379812. http://dx.doi.org/10.1016/j.ejps.2009.04.004

22. Ubrich, N.; Bouillot, P.; Pellerin, C. Hoffman, M. \& Maincent, P. - J. Control. Release., 97, p. 291 (2004). PMid:15196756. http://dx.doi org/10.1016/j.jconrel.2004.03.023

23. Kanakubo, Y.; Ito, F. \& Murakami, Y. - Colloids Surf. B Biointerfaces., 78, p. 85 (2010). PMid:20223642. http://dx.doi. org/10.1016/j.colsurfb.2010.02.017

24. Xu, X.; Xiang, Q.; He, Z.; Liu, Y.; Zhou, D.; Qin, X; Fan, T.; Zhang, Z.; Huang, Y. - Yakugaku Zasshi., 130, p. 409 (2010). PMid:20190525. http://dx.doi.org/10.1248/yakushi.130.409

25. Araujo, J.; Veja, E.; Lopes, C.; Egea, M. A.; Garcia, M.L. \& Souto, E. B. - Colloids Surf B Biointerfaces., 72, p. 48 (2009). PMid:19403277. http://dx.doi.org/10.1016/j.colsurfb.2009.03.028

26. Zhao, L. \& Feng, S. S. - J. Pharm. Sci., 99, p. 3552 (2010). PMid:20564384. http://dx.doi.org/10.1002/jps.22113

27. Ganea, G. M.; Sabliov, C. M.; Ishola, A. O.; Fakayode, S. O. \& Warner, I. M. - J. Nanosci. Nanotechnol., 8, p. 280 (2008). PMid:18468072.

28. Pangu, G. D.; Davis, K. P.; Bates, F. S. \& Hammer, D. A. - Macromol. Biosci., 14, p. 546 (2010). PMid:20491132. http://dx.doi.org/10.1002/ mabi.201000081

29. Mohammadi, G.; Valizadeh, H.; Barzegar-Jalali, M.; Lotfipour, F.; Adibkia, K.; Milani, M.; Azhdarzadeh, M.; Kiafar, F. \& Nokhodchi, A. - Colloids Surf B Biointerfaces., 80, p. 34 (2010). PMid:20558048. http://dx.doi.org/10.1016/j.colsurfb.2010.05.027

30. Legrand, P.; Lesieur, S.; Bochot, A.; Gref, R.; Raatjes, W.; Barratt, G.; Vauthier, C. - Int. J. Pharm., 344, p. 33 (2007). PMid:17616282. http:// dx.doi.org/10.1016/j.ijpharm.2007.05.054

31. Besheer, A.; Vogel, J.; Glanz, D.; Kressler, J.; Groth, T. \& Mader, K. - Mol. Pharm., 6, p. 407 (2009). PMid:19718794. http://dx.doi. org/10.1021/mp800119h

32. Derakhshandeh, K.; Soheili, M.; Dadashzadeh, S. \& Saghiri, R. - Int. J. Nanomedicine., 5, p. 463 (2010). PMid:20957168. PMCid:2950404. http://dx.doi.org/10.2147/IJN.S11586

33. Martins, D.; Frungillo, L.; Anazzetti, M. C.; Melo, P. S. \& Duran, N. - Int. J. Nanomedicine, 5, p. 77 (2010). PMid:20161989. PMCid:2819901. http://dx.doi.org/10.2147/IJN.S7833
34. Tan, Y.; Xu, K.; Li, L.; Liu, C.; Song, C. \& Wang, P. - ACS Appl. Mater. Interfaces, 1, p. 956 (2009). http://dx.doi.org/10.1021/am900054f

35. Stella, B.; Arpicco, S.; Rocco, F, Marsaud, V.; Renoir, J.M.; Cattel, L. \& Couvreur, P. - Int. J. Pharm., 344, p. 71 (2007). PMid:17651931. http://dx.doi.org/10.1016/j.ijpharm.2007.06.006

36. Arizaga, A.; Ibarz, G. \& Piñol R. - J. Colloid Interface Sci., 348, p. 668 (2010). PMid:20621828. http://dx.doi.org/10.1016/j.jcis.2010.05.051

37. Giannavola, C.; Bucolo, C.; Maltese, A.; Paolino, D.; Vandelli, M. A.; Puglisi, G.; Lee, V. H.; Fresta, M. - Pharm. Res., 200, p. 584 (2003). PMid:12739765. http://dx.doi.org/10.1023/A:1023290514575

38. Brigger, I.; Armand-Lefevre, L.; Chaminade, P.; Besnard, M.; Rigaldie, Y.; Largeteau A, Andremont, A.; Grislain, L.; Demazeau, G. \& Couvreur, P. - Pharm. Res., 20, p. 674 (2003). PMid:12739778. http:// dx.doi.org/10.1023/A:1023267304096

39. Mora-Huertas, C. E.; Fessi, H. \& Elaissari, A. - Int. J. Pharm., 385, p. 113 (2010). PMid:19825408. http://dx.doi.org/10.1016/j. ijpharm.2009.10.018

40. Fu, J.; Wang, D.; Wang, T.; Yang, W.; Deng, Y.; Wang, H.; Jin, S. \& He, N. - J. Biomed. Nanotechnol., 6, p.725 (2010). PMid:21361139. http:// dx.doi.org/10.1166/jbn.2010.1135

41. Bernardy, N.; Romio, A. P.; Barcelos, E. I.; Dal Pizzol, C.;Dora, C. L.; Lemos-Senna, E.; Araujo, P. H. \& Sayer, C. - J. Biomed. Nanotechnol., 6, p. 181 (2010).

42. Dong, X.; Mattingly, C. A.; Tseng, M.; Cho, M.; Adams, V. R. \& Mumper, R. J. - Eur. J. Pharm. Biopharm., 72, p. 9 (2009). PMid:19111929. PMCid:2663602. http://dx.doi.org/10.1016/j. ejpb.2008.11.012

43. Schaffazick, S. R.; Pohlmann, A. R.; Dalla-Costa, T. \& Guterres, S. S. Eur. J. Pharm. Biopharm., 56, p. 501 (2003). http://dx.doi.org/10.1016/ S0939-6411(03)00139-5

44. Guterres, S. S.; Weiss, V.; De Lucca, F. L.; Pohlmann, A. R. - Drug Deliv., 7, p. 195 (2000). http://dx.doi.org/10.1080/107175400455119

45. Alves, M. P.; Scarrone, A. L.; Santos, M.; Pohlmann, A. R. \& Guterres, S. S. - Int. J. Pharm., 341, p. 215 (2007). PMid:17482392. http://dx.doi. org/10.1016/j.ijpharm.2007.03.031

46. Kshirsagar, S. J.; Bhalekar, M. R.; Patel, J. N.; Mohapatra, S. K. \& Shewale, N. S. - Pharm. Dev. Technol., in press (2011). PMid:21428704. http://dx.doi.org/10.3109/10837450.2011.557732

47. Zhang, T.; Murowchick, J. \& Youan, B. B. - J. Pharm. Sci., 100, p. 1031 (2011). PMid:20928871. http://dx.doi.org/10.1002/jps.22341

48. Eley, J. G. \& Tirumalasetty, P. P. - J. Microencapsul., 20, p. 653 (2003).

49. Song, X.; Zhao, Y.; Wu, W.; Bi, Y.; Cai, Z.; Chen, Q.; Li, Y. \& Hou, S. - Int. J. Pharm., 350, p.320 (2008). PMid:17913411. http://dx.doi. org/10.1016/j.ijpharm.2007.08.034

50. McCarron, P. A.; Donnelly, R. F. \& Marouf, W. - J. Microencapsul., 23, p.480 (2006). PMid:16980271. http://dx.doi. org/10.1080/02652040600682390

51. Avgoustakis, K. - Curr. Drug Deliv., 4, p. 321 (2004). PMid:16305394. http://dx.doi.org/10.2174/1567201043334605

52. Ebrahimnejad, P.; Dinarvand, R.; Sajadi, S. A.; Atyabi, F.; Ramezani, F. \& Jaafari, M. R. - Pharm. Sci. Technol., 63, p. 512 (2009).

53. Sahana, B.; Santra, K.; Basu, S. \& Mukherjee, B. - Int. J. Nanomedicine., 5, p. 621 (2010).

54. Colombo, A. P.; Briançon, S.; Lieto, J. \& Fessi, H. - Drug Dev. Ind. Pharm., 27, p. 1063 (2001). PMid:11794809. http://dx.doi.org/10.1081/ DDC-100108369

Enviado: 12/04/11 Aceito: 27/06/11 